\title{
Sosialisasi dan Penyuluhan tentang Dagusibu dan Gema Cermat di Sekolah Dasar Muhammadiyah Jakarta Timur
}

\author{
Endang Sulistyaningsih ${ }^{1}$, Kori Yati ${ }^{*}$, dan Fahjar Prisiska \\ ${ }^{1}$ Fakultas Farmasi dan Sains, Universitas Muhammadiyah Prof. DR. Hamka, Jakarta \\ *Email: koriyati@uhamka.ac.id
}

\begin{abstract}
Abstrak
Upaya peningkatan kesehatan bagi masyarakat sangat penting. Hal ini diperkuat dengan dicanangkannya DAGUSIBU (Dapatkan, Gunakan, Simpan dan Buang Obat dengan benar) oleh Ikatan Apoteker Indonesia dan GEMA CERMAT (Gerakan Masyarakat Cerdas Akan Obat) oleh Kementerian Kesehatan Indonesia, agar masyarakat mampu memahami dan dapat melaksanakannya dalam upaya peningkatan kesehatan di lingkungan rumah dan sekolah. Tujuan dari kegiatan ini adalah memberikan sosialisasi, informasi, edukasi dan penyuluhan dilingkungan Sekolah Dasar Muhammadiyah 08 Plus dan 09 Plus Duren Sawit Jakarta Timur. Target yang ingin dicapai yaitu para wali murid dan civitas akademika SD Muhammadiyah 08 Plus dan 09 Plus Duren Sawit Jakarta Timur. Metode yang dilakukan beberapa tahap meliputi: pretest, penyampaian materi pengabdian, simulasi dengan alat peraga, diskusi dan tanya jawab, diakhiri dengan posttest. Hasil Pre Test dan Post Test yang diperoleh dianalisa secara statistik menggunakan Uji T-test dengan taraf kepercayaan $95 \%(\alpha=0,05)$. Berdasarkan hasil analisa diperoleh hasil yang sangat signifikan yaitu 0,000 . Pengolahan data dengan pendekatan secara teoritis dan analisa secara statistik dapat disimpulkan bahwa semua peserta belum mengetahui, memahami dan mengenal DAGUSIBU dan GEMA CERMAT, tetapi dengan adanya kegiatan sosialisasi ini peserta memahami akan pentingnya kesehatan.
\end{abstract}

Kata kunci: DAGUSIBU, GEMA CERMAT, Sekolah Dasar, Muhamamdiyah.

\begin{abstract}
Efforts to improve health for the community are very important. This is reinforced by the launching of DAGUSIBU (Get, Use, Store and Dispose of Drugs Correctly) by Indonesian Pharmacist Association and GEMA CERMAT (Gerakan Masyarakat Cerdas Akan Obat) by the Ministry of Health of Indonesia, so that the community can understand and can implement these in order to improve health in home and school environment. The purpose of this activity was to provide socialization, information, education and counseling at Muhammadiyah 08 Plus and 09 Plus Duren Sawit East Jakarta. Participant of this activity was the parents and the academic community of SD Muhammadiyah 08 Plus and 09 Plus Duren Sawit East Jakarta. Methods performed by several stages include: pretest, speech, simulation with props, discussion, and posttest. The results of Pre-Test and Post-Test obtained were analyzed statistically using T-test with 95\% confidence level $(\alpha=0,05)$. Based on the analysis results, there is a very significant result. Based on theoretical approach and statistical analysis can be concluded that all participants do not know, understand and recognize DAGUSIBU and GEMA CERMAT, but with this socialization activity the participants could understand more the importance of health.
\end{abstract}

Keywords: Dedication, DAGUSIBU, GEMA CERMAT, primary school, Muhammadiyah

Format Sitasi: Yati, K., Sulistyaningsih, E., \& Prisiska, F. (2019). Sosialisasi dan Penyuluhan tentang Dagusibu dan Gema Cermat di Sekolah Dasar Muhammadiyah Jakarta Timur. Jurnal Solma, 08(1), 127135. Doi: http://dx.doi.org/10.29405/solma.v8i1.1058

Diterima: 01 Januari 2018 | Revisi: 01 April 2019 | Dipublikasikan: 30 April 2019. 


\section{PENDAHULUAN}

Gema cermat merupakan upaya bersama pemerintah dan masyarakat dalam meningkatkan kesadaran, kepedulian dan pemahaman masyarakat tentang penggunaan obat secara benar, dimana melalui Gema Cermat, diharapkan penggunaan obat secara rasional oleh masyarakat dapat tercapai. Menurut WHO penggunaan obat dikatakan rasional apabila pasien menerima obat yang sesuai dengan kebutuhan klinisnya, dalam dosis sesuai dengan kebutuhan dan dalam periode waktu yang adekuat. Peresepan obat dan penggunaan obat yang tidak tepat, rumah tangga menyimpan obat untuk swamedikasi dan perolehan antibiotik tanpa resep dokter, merupakan perilaku yang salah atau tidak rasional dari masyarakat kita terkait swamedikasi. Akibatnya bisa membahayakan masyarakat karena kemungkinan terjadi efek samping obat yang tidak diinginkan serta berdampak pada ancaman meningkatnya resistensi terhadap antibiotika (Anonim, 2017).

Saat ini, dengan meningkatnya kemajuan teknologi berbasis online masyarakat perlu mewaspadai iklan obat yang menyesatkan yang banyak ditayangkan di media cetak, online, maupun elektronik. Seharusnya iklan obat harus seimbang antara edukasi dengan kepentingan komersial. Untuk meminimalkan pengaruh buruk maka informasi dalam iklan yang berlebihan dan menyesatkan, menawarkan harga yang jauh lebih murah, hingga menjanjikan cepat sembuh, efek instan dan menawarkan garansi, maka perlu diberikan edukasi kepada masyarakat (Anonim, 1994, 2016).

Seorang Apoteker diharapkan memiliki komitmen dan kemampuan mempengaruhi perilaku masyarakat dan tenaga kesehatan dalam rangka pemberdayaan masyarakat untuk meningkatkan penggunaan obat secara rasional. Aktif melaksanakan pengabdian pada masyarakat (seperti bakti sosial, pengobatan gratis, penyuluhan/promosi kesehatan-CBIADAGUSIBU). Memiliki kemampuan berkomunikasi yang baik public speaking), memiliki jiwa edukatif. Berhasil mengelola dan memberikan pelayanan kefarmasian dengan baik di apotek/klinik/PKM termasuk melaksanakan PIO konseling, homecare yang terdokumentasi terhadap masyarakat di sekitar (Anonim, 2017).

Fakultas Farmasi dan Sains Universitas Muhammadiyah Prof. DR. HAMKA (UHAMKA) merupakan salah satu Fakultas sebagai bagian dari UHAMKA yang merupakan salah satu jenis amal usaha Muhammadiyah yang berada di kampus C UHAMKA yang berada pada lingkungan perumnas Klender di Jalan Delima II/IV, Jakarta Timur. Dosen-dosen FFS UHAMKA umumnya berprofesi sebagai Apoteker. Apoteker adalah sarjana farmasi yang telah lulus sebagai Apoteker dan telah mengucapkan sumpah 
jabatan Apoteker. Salah satu peran Apoteker dalam pekerjaan kefarmasian meliputi pelayanan informasi Obat (PP 51 tahun 2009). Apoteker FFS UHAMKA merupakan Anggota dari IAI pada PC IAI Jakarta Timur. Sebelumnya telah dilakukan pelatihan pengolahan obat di UKS sekolah-sekolah Muhammadiyah wilayah DKI Jakarta tentang pengelolaan obat yang benar, menunjukkan dengan adanya kegiatan itu ada peningkatan pengetahuan dan pemahaman guru pengelola UKS (Yati, Hariyanti, Dwitiyanti, Lestari, \& Pramulani, 2018)

Mengingat pentingnya peranan Apoteker dalam menyampaikan informasi Obat dan sesuai dengan tujuan IAI dalam mencanangkan Gerakan Keluarga Sadar Obat (GKSO), masyarakat sekitar wilayah kampus perlu mengetahui lebih tentang informasi bagaimana penanganan obat secara tepat. Maka perlu dilakukan sosialisasi tentang DAGUSIBU Obat. Dengan memberikan pengetahuan tentang pentingnya penanganan Obat lewat 'DAGUSIBU dan Gema Cermat' diharapkan masyarakat lingkungan Muhammadiyah di DKI Jakarta dapat pemahaman yang tepat tentang obat dan dapat dihindari penggunasalahan dan penyalahgunaan obat dan pengobatan akan menjadi lebih tepat di masyarakat.

Oleh karena itu, kami dari tim dosen Fakultas Farmasi dan Sains UHAMKA melaksanakan kegiatan pengabdian masyarakat bagi para wali murid dan civitas akademika SD Muhammadiyah 08 Plus dan 09 Plus Duren Sawit Jakarta Timur.

\section{MASALAH}

Kesehatan dan tumbuh kembang anak usia sekolah menjadi tanggung jawab guru dan para orangtua di lingkungan sekolah. Pengetahuan dan pemahaman yang kurang tentang cara mendapatkan, menggunakan, menyimpan, dan membuang obat dengan benar menjadi permasalahan tersendiri (Kementrian Kesehatan RI, 2015).

Peran guru dan orangtua dalam peningkatan kesehatan bagi anak, baik dirumah ataupun disekolah perlu adanya perhatian khusus seperti :

a. Perlu adanya pemahaman tentang cara mendapatkan obat yang benar dan tepat

b. Perlu adanya pemahaman tentang cara penggunaan obat yang baik dan tepat

c. Perlu adanya pemahaman tentang cara menyimpan obat yang baik dan benar

d. Perlu adanya pemahaman tentang cara membuang obat yang baik dan benar

Semua penjelasan diatas termasuk dalam program Upaya Peningkatan Kesehatan dari Kementrian Kesehatan yang tertuang dalam DAGUSIBU. 
Manfaat dari Program Kemitraan Masyarakat ini meningkatkan pemahaman akan pentingnya DAGUSIBU dalam upaya peningkatan kesehatan di Lingkungan Sekolah Dasar Muhammadiyah 08 Plus dan 09 Plus Duren Sawit Jakarta Timur.

\section{Solusi yang ditawarkan}

Berdasarkan permasalahan diatas, Tim Dosen FFS UHAMKA menawarkan solusi untuk mengatasi hal tersebut dengan melakukan pengabdian" Sosialisasi dan Penyuluhan Tentang DAGUSIBU dan GEMA CERMAT di Sekolah Dasar Muhammadiyah 08 Plus dan 09 Plus Duren Sawit Jakarta Timur".

Peserta pengabdian merupakan orang yang tepat untuk diberikan pemahaman tentang penanganan obat, karena peserta berkaitan dalam pembelian, penyimpanan, penggunaan dan pembuangan di lingkungan Sekolah Dasar Muhammadiyah 08 Plus dan 09 Plus Duren Sawit Jakarta Timur. Jika peserta telah memahami dengan baik, sehingga dapat meningkatkan kualitas kesehatan siswa di sekolah, meningkatkan kualitas pengadaan obatobat di sekolah karena penangannya lebih tepat.

Program pengabdian yang ditawarkan berupa penyuluhan, pemaparan materi, simulasi dan pendistribusian leaflet/brosur untuk seluruh civitas di lingkungan Sekolah Dasar Muhamamdiyah 08 Plus dan 09 Plus Duren Sawit Jakarta Timur.

\section{METODE PELAKSANAAN}

Metode yang dilakukan untuk menginformasikan tentang pola hidup sehat yang bias dilakukan sehari - hari dalam upaya peningkatan kesehatan di masyarakat. Sosialisasi informasi diatas dilakukan dalam 2 hari dan tempat yang berbeda, yaitu : SD Muhammadiyah 08 Plus yang dilaksanakan pada tanggal 18 Januari 2018 dan SD Muhammadiyah 09 Plus yang dilaksanakan pada tanggal 13 Desember 2017.

\section{Hari Pertama tanggal 13 Desember 2017 SD Muhamamdiyah 09 Plus}

Edukasi pola hidup sehat dari pemakaian obat yang tepat di Sekolah Dasar Muhamamdiyah 09 Plus Duren Sawit Jakarta Timur. Edukasi pola hidup sehat dalam kegiatan tersebut berupa :

a. Pendahuluan : penjelasan secara detail tentang upaya peningkatan kesehatan yang sesuai dengan program pemerintah seperti DAGUSIBU dan GEMA CERMAT. Informasi ini disampaikan melalui presentasi oleh pemateri dan penayangan video tentang pola hidup sehat dan penyebaran brosur/leaflet. 
b. Simulasi melakukan simulasi dan diskusi tanya jawab secara interaktif antara pemateri dengan peserta berupa pertanyaan kepada audiens disertai dengan pemberian soal pre test dan post test.

c. Pembagian doorprize : agar peserta berperan aktif dalam diskusi dan tanya jawab maka tim pengabdian memberikan hadiah kepada peserta yang aktif dalam diskusi.

\section{Hari Kedua tanggal 18 Januari 2018 SD Muhammaidyah 08 Plus}

Edukasi pola hidup sehat dari pemakaian obat yang tepat di Sekolah Dasar Muhamamdiyah 08 Plus Duren Sawit Jakarta Timur. Edukasi pola hidup sehat dalam kegiatan tersebut berupa :

a. Pendahuluan : penjelasan secara detail tentang upaya peningkatan kesehatan yang sesuai dengan program pemerintah seperti DAGUSIBU dan GEMA CERMAT. Informasi ini disampaikan melalui presentasi oleh pemateri dan penayangan video tentang Pola Hidup sehat dan penyebaran brosur/leaflet.

b. Simulasi melakukan simulasi dan diskusi Tanya jawab secara interaktif antara pemateri dengan peserta berupa pertanyaan kepada audiens disertai dengan pemberian soal pre test dan post test.

c. Pembagian doorprize : agar peserta berperan aktif dalam diskusi dan Tanya jawab maka tim pengabdian memberikan hadiah kepada peserta yang aktif dalam diskusi.

\section{Tempat Pelaksanaan}

\section{Pelaksanaan Kegiatan Mitra 1}

Pelaksanaan Kegiatan Mitra 1 dilakukan di Sekolah dasar Muhamamdiyah 08 Plus dengan alamat J1. Bunga Rampai X Duren Sawit Jakarta Timur dengan jarak tempuh kurang lebih $5 \mathrm{Km}$ dari kampus FFS UHAMKA.

\section{Pelaksanaan Kegiatan Mitra 2}

Pelaksanaan Kegiatan Mitra 2 dilakukan di Sekolah dasar Muhamamdiyah 09 Plus dengan alamat Jl. SMA 71 No. 18 Duren Sawit Jakarta Timur dengan jarak tempuh kurang lebih $1 \mathrm{Km}$ dari kampus FFS UHAMKA.

\section{Waktu Pelaksanaan}

1. Waktu pelaksanaan kegiatan sosialisasi dan penyuluhan pada Mitra 1 yaitu di SD Muhammadiyah 08 Plus Duren Sawit dilaksanakan pada tanggal 18 Januari 2018.

2. Waktu pelaksanaan kegiatan sosialisasi dan penyuluhan pada Mitra 2 yaitu di SD Muhammadiyah 09 Plus Duren Sawit dilaksanakan pada tanggal 13 Desember 2017. 


\section{PEMBAHASAN}

\section{Persiapan}

Persiapan pengabdian masyarakat yang berjudul "Sosialisasi Dan Penyuluhan Tentang Dagusibu Dan Gema Cermat Di Sekolah Dasar Muhammadiyah 08 Plus Dan 09 Plus Duren Sawit Jakarta Timur" diawali dengan menentukan masyarakat yang menjadi target sosialisasi. Setelah target didapatkan, yakni DIKDASMEN PWM DKI Jakarta, langkah selanjutnya adalah penandatanganan kontrak kerja dengan pihak Kepala Sekolah SD Muhammadiyah 08 Plus dan 09 Plus Jakarta Timur. Adapun hal yang kami sepakati untuk pengabdian ini adalah sebagai berikut:

a. Materi yang disampaikan adalah tentang DAGUSIBU dan Gema Cermat;

b. Pemateri yang disepakati adalah Endang Sulistyaningsih, M. Kes., Apt dan Fahjar Prisiska, M. Farm., Apt.

c. Menyepakati metode penyampaian yang akan digunakan

Setelah menemui perwakilan dari pihak Sekolah Dasar Muhamamdiyah 08 Plus dan 09 Plus Jakarta Timur maka kita adakan persiapan tim pengabdian. Adapun beberapa hal yang dilakukan dalam persiapan sebelum melakukan pengabdian adalah:
a. Rapat koordinasi tim pengabdian;
b. Perumusan dan pembuatan materi pengabdian;
c. Menyepakati teknis kegiatan pengabdian;
d. Mempersiapan doorprize untuk peserta;
e. Menyepakati waktu pelaksanaan kegiatan

Selanjutnya tim pengabdian melakukan koordinasi dengan pihak SD Muhammadiyah 08 Plus dan 09 Plus Jakarta Timur untuk jadwal dan teknis kegiatan. Kedua pihak menyepakati tim pengabdian bertugas menyiapkan tempat dan pihak SD Muhammadiyah 08 Plus dan 09 Plus Jakarta Timur bertugas mengkondisikan peserta untuk kegiatan pengabdian.

\section{Pelaksanaan Kegiatan}

Pelaksanaan pengabdian diawali dengan edukasi dan sosilasisasi DAGUSIBU dan Gema Cermat. Kegiatan yang dilakukan adalah sosialisasi pada guru dan wali murid dengan menggunakan media brosur. Materi disosialisaikan oleh ibu Endang Sulistyaningsih, M.Kes., Apt dan bapak Fahjar Prisiska, M.Farm., Apt. Setelah berakhirnya kegiatan, kami membagikan doorprize pada peserta yang mengajukan 
pertanyaan dan aktif dalam Kegiatan Pengabdian kepada Masyarakat. Kegiatan diakhiri dengan post test dan foto bersama.

Pelaksanaan pengabdian berikutnya dilaksanakan pada hari berikutnya. Hari senin, tanggal 14 Januari 2018 pukul 08.00 WIB peserta tiba di Sekolah Dasar Muhammadiyah 08 Plus pukul 13.00 WIB dan disambut oleh ketua pelaksana pengabdian dengan antusias. Selanjutnya pihak sekolah mengkondisikan peserta dan memberikan sambutan serta pengarahan awal pada peserta yang menjadi sasaran pada kegiatan ini, dalam hal ini disampaikan oleh Ibu Kepala Sekolah SD Muhammadiyah 08 Plus.

Kegiatan dimulai tepat pada pukul 13.00 WIB. Kegiatan dilakukan daloam satu sesi. Yakni edukasi dan sosialisasi mengenai Sosialisasi DAGUSIBU dan Gema Cermat oleh Bapak Fahjar Prisiska, M. Farm., Apt. Acara dimulai dengan perkenalan dan penjajakan awal mengenai materi pengetahuan peserta tentang DAGUSIBU dan Gema Cermat. Penjajakan pengetahuan dilakukan dengan memberikan pre test. Jawaban pre test dari peserta menjadi tolok ukur pengetahuan dasar tentang materi yang akan disampaikan. Ada beberapa peserta yang memiliki pengetahuan yang baik mengenai DAGUSIBU dan Gema Cermat, dan sebagian lagi masih ada yang belum memahami apa itu DAGUSIBU dan Gema Cermat. Peserta sangat antusias ketika disampaikan mengenai DAGUSIBU dan Gema Cermat. Pada sesi pertama peserta terlihat tertarik dengan materi yang disampaikan.

\section{Analisa Data Pre Test dan Post Test SD Muhammadiyah 08 Plus Jakarta Timur}

Berdasarkan Analisa pre test dan post test pada Sekolah Dasar Muhammadiyah 08 Plus Jakarta Timur adalah sebagai berikut :

a. Hasil Data Analisa Distribusi Normal : data terdistribusi secara normal dan merata seluruh anggota

b. Hasil data variasi uji lanutnya dengan $T$ Test dengan membandingkan hasil Uji Pretest (sebelum di sosialisasikan) dengan Post Test setelah diberikan pemahaman tentang DAGUSIBU dan Gema Cermat memiliki perbedaan bermakna. Hal ini menunnjukkan variasi bahwa tidak semua peserta banyak yang belum mengetahui dan memahami apa itu DAGUSIBU dan Gema Cermat. Hal ini ditunjukkan dari hasil statistik hasil signifikansinya 0,000 .

\section{Analisa Data Pre Test dan Post Test SD Muhammadiyah 09 Plus Jakarta Timur}

Berdasarkan Analisa pre test dan post test pada Sekolah Dasar Muhammadiyah 09 Plus Jakarta Timur adalah sebagai berikut : 
a. Hasil Data Analisa Distribusi Normal: data terdistribusi secara normal dan merata seluruh anggota

b. Hasil data variasi uji lanutnya dengan T- Test dengan membandingkan hasil Uji Pretest (sebelum di sosialisasikan) dengan Post Test setelah diberikan pemahaman tentang DAGUSIBU dan Gema Cermat memiliki perbedaan bermakna. Hal ini menunnjukkan variasi bahwa tidak semua peserta banyak yang belum mengetahui dan memahami apa itu DAGUSIBU dan Gema Cermat. Hal ini ditunjukkan dari hasil statistik hasil signifikansinya 0,000 .

\section{KESIMPULAN}

Berdasarkan hasil analisa diperoleh hasil yang sangat signifikan yaitu 0,000. Pengolahan data dengan pendekatan secara teoritis dan analisa secara statistik dapat disimpulkan bahwa semua peserta belum mengetahui, memahami dan mengenal DAGUSIBU dan Gema Cermat, tetapi dengan adanya kegiatan sosialisasi ini peserta memahami akan pentingnya kesehatan.

\section{UCAPAN TERIMA KASIH}

Terima kasih kepada LPPM (Lembaga Penelitian Pengabdian Masyarakat) UHAMKA sebagai pemberi dana kegiatan Sosialisasi Dan Penyuluhan Tentang Dagusibu Dan Gema Cermat Di Sekolah Dasar Muhammadiyah 08 Plus Dan 09 Plus Duren Sawit Jakarta Timur.

\section{DAFTAR PUSTAKA}

Anonim. (1994). Keputusan Menkes RI No. 386/Menkes/SK/IV/1994 Tentang Pedoman Periklanan: Obat Bebas, Obat Tradisional, Alat Kesehatan, Kosmetik, Perbekalan Kesehatan Rumah Tangga dan Makanan-Minuman.

Anonim. (2016). BPOM : Waspadai Iklan Obat yang Menyesatkan. www.ikatanapotekerindonesia.net. Diakses 25 Januari 2018. Retrieved January 25, 2018, from www.ikatanapotekerindonesia.net.

Anonim. (2017). Gema Cermat Bantu Masyarakat Pahami Penggunaan Obat Yang Rasional. Retrieved January 25, 2018, from www.diskes.baliprov.go.id.

Kementrian Kesehatan RI, K. K. R. (2015). Cara Penggunaan Obat. Jakarta: Dirjen Binfar Kemenkes RI. 
Yati, K., Hariyanti, Dwitiyanti, Lestari, \& Pramulani, M. (2018). Pelatihan Pengelolaan Obat yang Tepat dan Benar di UKS Sekolah-Sekolah Muhammadiyah Wilayah DKI Jakarta. Journal SOLMA, 1(01), 42-49.

\section{(c) (i)}

(C) 2019 Oleh authors. Lisensi Jurnal Solma, LPPM-Uhamka, Jakarta. Artikel ini bersifat open access yang didistribusikan di bawah syarat dan ketentuan Creative Commons Attribution (CC BY) license. (http://creativecommons.org/licenses/by/4.0/) 